\title{
СОДЕРЖАНИЕ ТЯЖЕЛЫХ МЕТАЛЛОВ В ПЛОДАХ ШИПОВНИКА МАЙСКОГО КАК ФАКТОР УХУДШЕНИЯ ЗДОРОВЬЯ НАСЕЛЕНИЯ
}

\author{
Лукьянчикова Оксана Владимировна \\ к.б.н., доцент \\ Шевченко Дарья Витальевна \\ студент \\ ФГБОУ ВО «Курский государственный \\ медицинский университет»
}

Аннотация: Исследовано содержания свинца, кадмия и цинка в плодах шиповника майского (Rosa majalis Herrm), произрастающего на территории Октябрьского района Курской области в местах с различной интенсивностью антропогенной нагрузки. Проведена его оценка на соответствие требованиям нормативных документов. Результаты исследования показали, что плоды $R$. majalis Herrm могут использоваться населением для сбора и различных заготовок.

Ключевые слова: Шиповник майский (Rosa majalis Herrm), тяжелые металлы, свинец, цинк, кадмий, содержание, предельно-допустимая концентрация, антропогенная нагрузка.

\section{THE CONTENT OF HEAVY METALS IN THE FRUITS OF ROSEHIP MAY AS A FACTOR IN THE DETERIORATION OF PUBLIC HEALTH}

\section{Lukyanchikova Oksana Vladimirovna Shevchenko Daria Vitalievna}

\begin{abstract}
The content of lead, cadmium and zinc in the fruits of the rosehip May (Rosa majalis Herrm), growing on the territory of the Oktyabrsky district of the Kursk region in places with different intensity of anthropogenic load, has been studied. Its assessment for compliance with the requirements of regulatory documents was carried out. The results of the study showed that the fruits of $R$. majalis Herrm can be used by the population for harvesting and various preparations.
\end{abstract}


Key words: Rosehip May (Rosa majalis Herrm), heavy metals, lead, zinc, cadmium, content, maximum permissible concentration, anthropogenic load.

Шиповник является ценным лесомелиоративным и декоративным кустарником. Благодаря неприхотливости и высокой засухоустойчивости его достаточно часто используют для озеленения различных территорий населенных пунктов. Он входит в состав зеленых насаждений жилых микрорайонов, парков, скверов и садов.

Наряду с этим растения рода шиповник имеют и фармакологическую ценность, которая, прежде всего, определяется комплексом биологически активных веществ в их плодах. В них содержится аскорбиновая кислота, витамины группы В, К , Р, Е, каротиноиды, флавоноиды, катехины, пектиновые вещества, органические кислоты, соли калия, натрия, кальция, магния, фосфора, железа [1, с. 139].

Плоды шиповника и лечебные препараты из них оказывают сильное антиоксидантное и общеукрепляющее действие, стимулируют сопротивляемость организма к инфекциям, уменьшают проницаемость сосудов, усиливают синтез гормонов и регенерацию тканей, обладают противовоспалительными, иммуностимулирующими и желчегонными свойствами, [1, с. 139]. В быту плоды шиповника используются для приготовления варений, повидла, отваров и различных видов чая.

В тоже время химический состав растений, накопление в них макро- и микроэлементов во многом зависят от экологических условий местообитания [2, с. 29; 3, с. 254]. Загрязнение окружающей среды тяжёлыми металлами приводит к накоплению их в различных органах растений [2, с. 29; 3, с. 254], в том числе и плодах шиповника. Путем миграции по трофическим цепям, эти элементы попадают в организм человека, вызывая патологические изменения внутренних органов, единовременные или хронические отравления и приводят к серьезным нарушениям процессов обмена веществ и жизненно важных функций организма [4, с. 5]. В результате вместо положительного эффекта, обогащенные тяжелыми металлами растения могут наносить вред здоровью человека.

В связи с этим целью работы являлось исследование содержания тяжелых металлов в плодах растений рода шиповник, произрастающих на территории Октябрьского района Курской области. 
Плоды шиповника майского собирали в сухую солнечную погоду в период их полного созревания - в конце сентября 2021 года в местах произрастания с различной интенсивностью антропогенной нагрузки:

- в природной экосистеме широколиственного леса, находящейся вдали от источников загрязнения (32 км от города Курска, 25,7 км от города Курчатов и 4 км от автотрассы) и практически не подвергающейся прямому антропогенному воздействию;

- селитебной зоне, застроенной преимущественно одноэтажными домами (улица Мирная Октябрьского района Курской области);

- однорядовых насаждениях вдоль автотрассы «Курск - Курчатов» на расстоянии 4 м от нее, характеризующейся высокой интенсивностью движения (улица Октябрьская Октябрьского района Курской области).

На исследуемых участках выбирали 2-3 экземпляра и на расстоянии около 1,5 м от поверхности почвы с внешней стороны каждого растения по окружности собирали плоды без видимых признаков повреждений. После естественной сушки и хранения в помещении при температуре $18-22^{\circ} \mathrm{C}$ в течение 30 дней, из отобранного в одной точке материла формировали обобщенную смешанную пробу.

Содержание тяжелых металлов определяли в сухом растительном сырье. В качестве информативных показателей выбраны концентрации свинца, кадмия и цинка, как наиболее характерные выбросы автотранспорта и приоритетные загрязняющие вещества промышленных предприятий. Кроме того, их соединения отличаются распространенностью, токсичностью, хорошей растворимостью и вследствие этого высокой миграционной способностью, и возможностью к биоаккумуляции [5, с. 173]

Подвижные формы тяжелых металлов определяли атомноабсорбционным методом на базе ФГБУ ГСАС «Курская» с использованием анализатора «Спектр-5-4» с ртутно-гидридной системой РГС-1-1. Анализы выполнялись в трехкратной повторности. Статистическую обработку экспериментальных данных и графическое представление материала проводили с использованием пакета анализа Microsoft Excel и Statsoft Statistica 10.0. О достоверности оценок судили по t-критерию Стьюдента.

В настоящее время не существует утвержденных нормативов, регламентирующих содержание тяжелых металлов в лекарственном растительном сырье [2, с. 31]. В связи с этим многие авторы [2, с. 31; 3, с. 255; 5, с. $175 ; 6$, с. 155] в качестве наиболее близкого эталона ПДК для 
лекарственного растительного сырья используют для таких элементов как свинец и кадмий - их предельно допустимые содержания, приведенные в методике ОФС.1.5.3.0009.15. «Определение содержания тяжелых металлов и мышьяка в лекарственном растительном сырье и лекарственных растительных препаратах», а для цинка и меди - предельно допустимые уровни и концентрации, установленные для сухих овощей и фруктов [7, 8, 9, 10, 11$]$.

Результаты наших исследований показали, что содержание свинца в исследуемых образцах плодов шиповника майского варьировало от 1,52 мг/кг до 5,02 мг/кг (рис. 1). При этом минимальное значение данного элемента наблюдалось в плодах этого кустарника, произрастающего в экосистеме смешанного леса. Так, содержание свинца в исследуемом растительном материале, отобранном в лесной экосистеме было в 2,9 раз меньше, чем в образцах, отобранных в селитебной зоне на улице Мирной и в 3,3 раза - чем в однорядовых насаждениях вдоль автотрассы с высокой интенсивностью движения улицы Октябрьской.

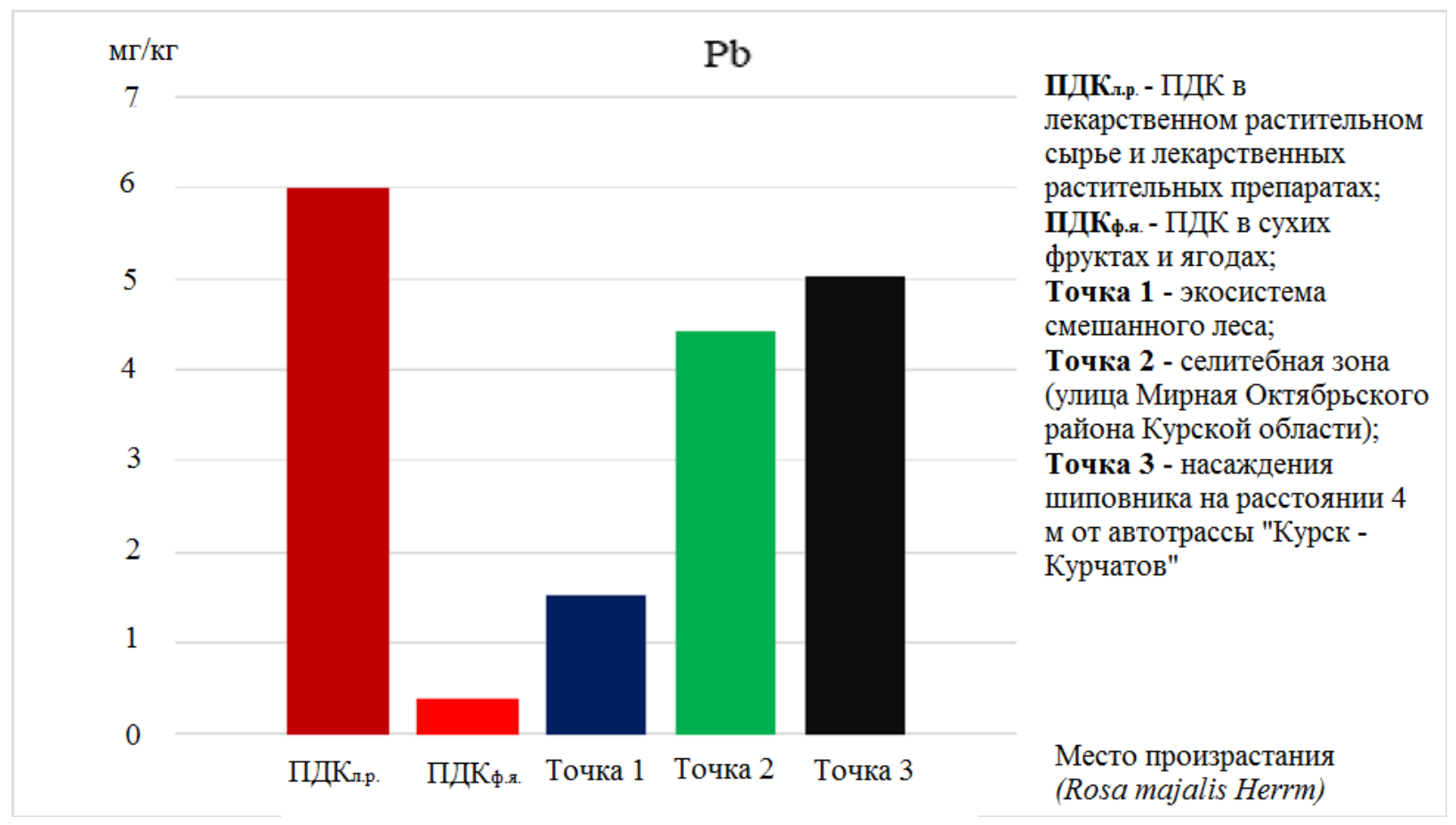

Рис. 1. Содержание свинца в плодах шиповника майского (Rosa majalis Herrm) в зависимости от места произрастания 
Статистическая обработка экспериментальных данных с использованием параметрического критерия Стьюдента показала, что такие различия являются достоверными на 95-99\% уровнях значимости.

Выявленные концентрации свинца в плодах шиповника майского не превышают ПДК по тяжелым металлам, предложенным Государственной фармакопеей для лекарственного растительного сырья и лекарственных растительных препаратов. Однако они выше в 3,8-12,55 раз в зависимости от места произрастания этого кустарника ПДК для сухих овощей и фруктов (рис. 1), что ставит, по мнению некоторых авторов под сомнение правомерность такого сравнения [2, с. 31].

По данным ряда исследователей [2, с. 31] свинец присутствует в природных условиях во всех растениях, однако его роль в их метаболизме не установлена. Среднее его содержание в составе растительности, произрастающей на незагрязненных почвах, составляет 4,1 мг/кг сухой массы [2, с. 31]. Несколько более высокое его количество (5,02 мг/кг), превышающее такое среднее значение в растениях наблюдалось в образцах плодов шиповника, отобранных в его насаждениях вдоль автотрассы «Курск Курчатов» на расстоянии 4 м от нее. Вероятно, это обусловлено негативным воздействием автомобилей на почвенный покров придорожной полосы, связанным с поступлением в него свинца с выхлопными газами автотранспорта, а также в результате износа шин и последующей его аккумуляцией в почве и растительности [3, с. 254; 12 , с. 73]. Содержание этого тяжелого металла в растениях очень чувствительно к влиянию антропогенного фактора [13, с. 45].

Количество кадмия варьировало от 0,045 мг/кг в плодах шиповника селитебной зоны и 0,05 мг/кг - смешанного леса, различия между которыми были не достоверны на 95\% уровне значимости до 0,08 мг/кг - в образцах, отобранных на улице Октябрьской с высокой интенсивностью движения (рис. 2) и не превышало ПДК для лекарственных растений и лекарственных растительных препаратов. 


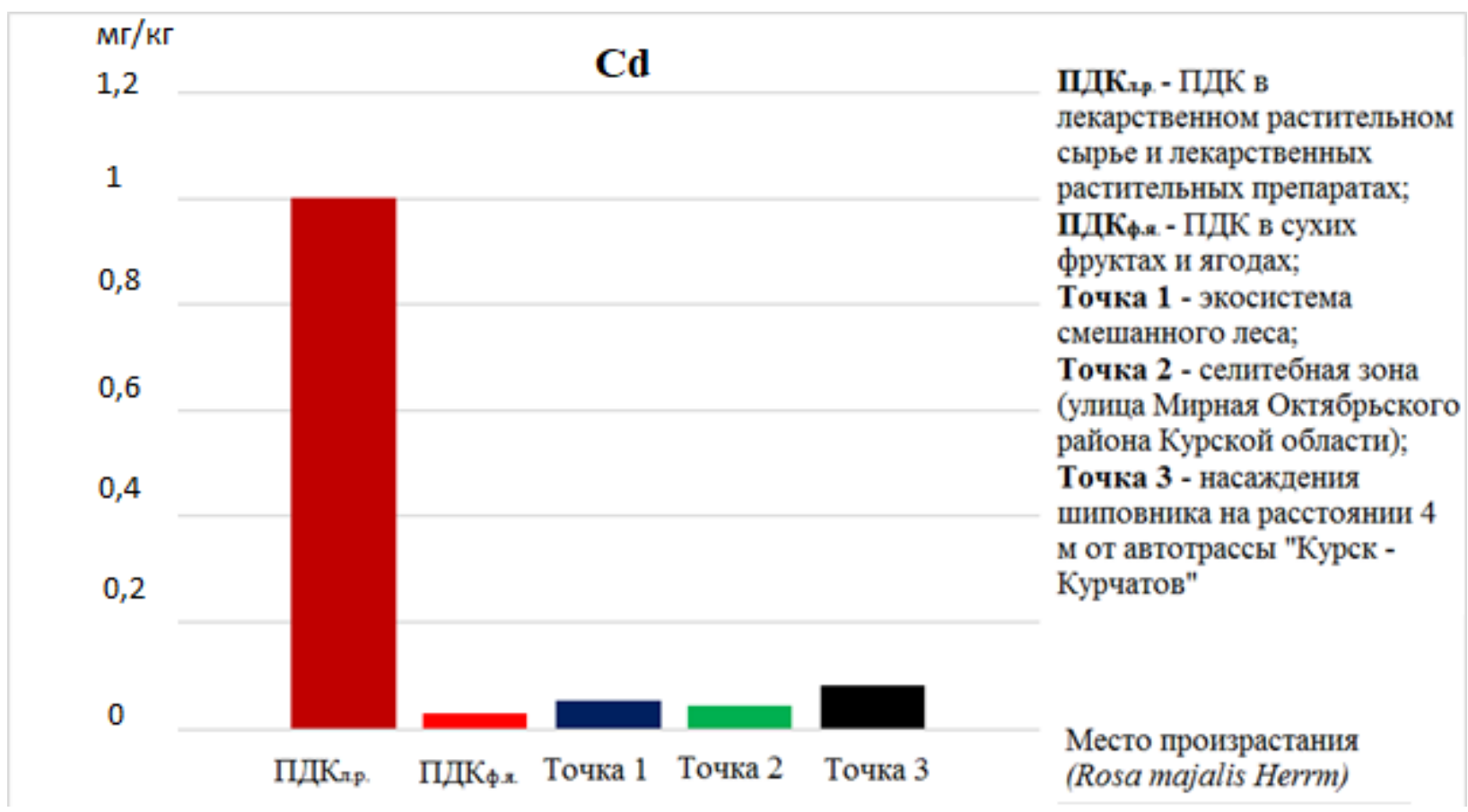

\section{Рис. 2. Содержание кадмия в плодах шиповника майского (Rosa majalis Herrm) в зависимости от места произрастания}

Повышенные концентрации этого элемента по сравнению с ПДК для сухих овощей и фруктов выявлены в плодах шиповника, произрастающего в лесной экосистеме и однорядовых насаждениях вдоль автомагистрали, в которых содержание кадмия достоверно было выше соответственно в 1,7 и 2,7 раз.

В то же время полученные результаты согласуются с российскими и зарубежными литературными данными, согласно которым содержание этого элемента в препаратах на основе растений редко превышает 0,8 мг/кг [5, с. 176].

Содержание цинка в плодах шиповника майского, произрастающего в местах с различной степенью антропогенной нагрузки было приблизительно одинаковым и колебалось от 7,51 до 8,57 мг/кг (рис. 3). Различия в количестве этого элемента в исследуемых образцах не достоверны на $95 \%$ уровне $\left(\mathrm{t}_{\text {факт }}=\right.$ $1,285 ; 1,420 ; 2,693)$. 


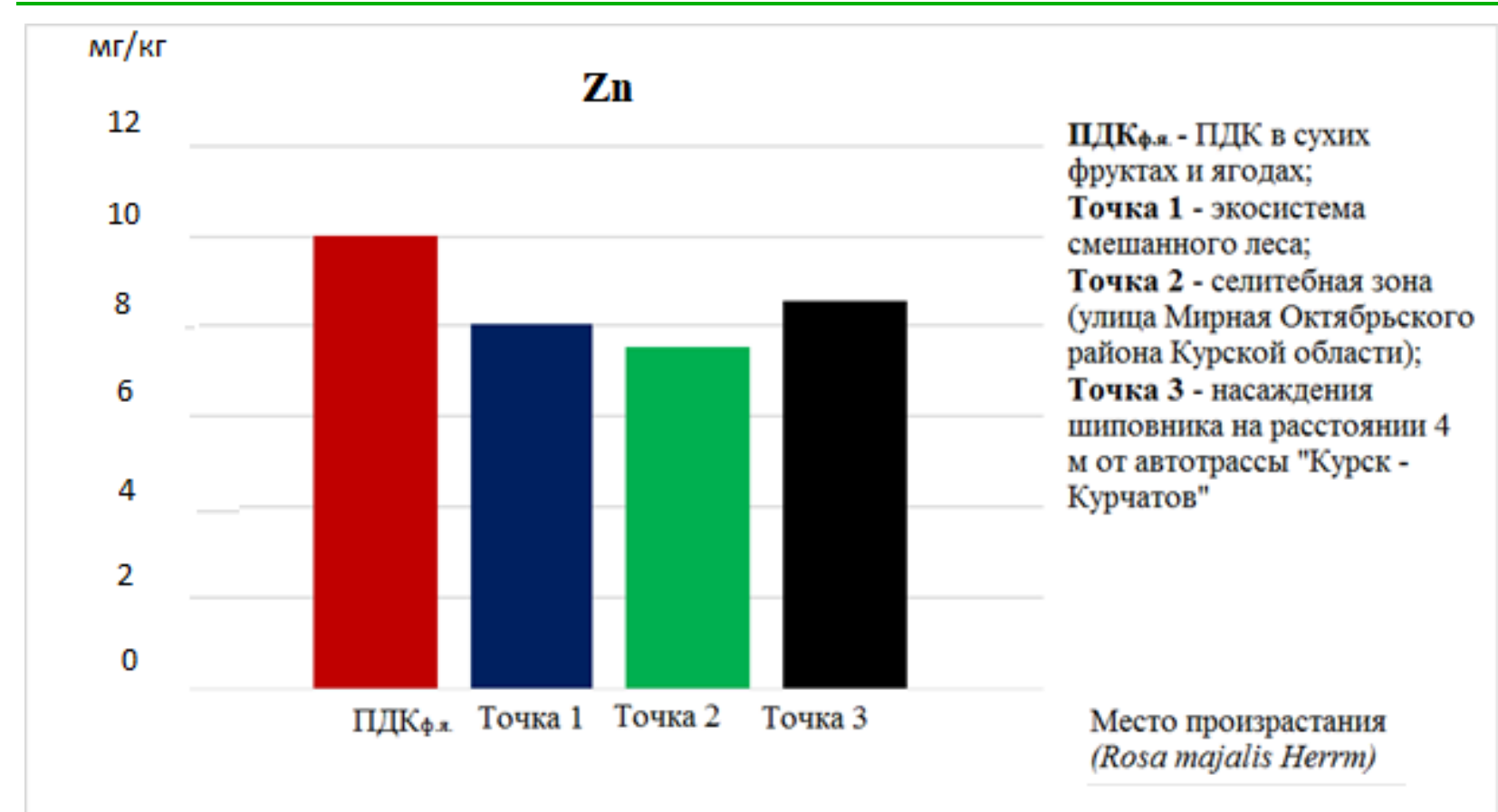

\section{Рис. 3. Содержание цинка в плодах шиповника майского} (Rosa majalis Herrm) в зависимости от места произрастания

В соответствие с имеющимися нормативными документами содержание цинка в лекарственном растительном сырье и лекарственных растительных препаратах не регламентируется. В тоже время полученные в ходе исследования данные удовлетворяют существующей норме (ПДК), установленной для сухих фруктов и ягод.

Согласно данным обобщенного Ж. А. Димиденок (2019) мирового материала [14, с. 52] в целом содержание рассматриваемых тяжелых металлов в плодах шиповника майского, произрастающего на территории Октябрьского района Курской области находится в пределах нетоксичных концентраций (табл. 1).

Таблица 1

Интервалы примерных концентраций тяжелых металлов в растительном веществе (обобщённый мировой материал), мг/кг сухой массы

(по Димиденок Ж. А., 2019)

\begin{tabular}{|c|c|c|}
\hline \multirow{2}{*}{$\begin{array}{c}\text { Тяжелые } \\
\text { металлы }\end{array}$} & \multicolumn{2}{|c|}{ Концентрация } \\
\cline { 2 - 3 } & Достаточная (нормальная) & Избыточная (токсичная) \\
\hline $\mathrm{Cu}$ & $5-30$ & $20-100$ \\
\hline $\mathrm{Zn}$ & $27-150$ & $100-400$ \\
\hline
\end{tabular}


Продолжение Таблицы 1

\begin{tabular}{|c|c|c|}
\hline $\mathrm{Cd}$ & $0,05-0,2$ & $5-30$ \\
\hline $\mathrm{Pb}$ & $5-10$ & $30-300$ \\
\hline
\end{tabular}

По-видимому, это определяется низким количеством микроэлементов в почвенном покрове мест произрастания данного кустарника и отсутствием его сильного антропогенного загрязнения.

Таким образом установлено, что во всех плодах шиповника содержатся тяжелые металлы. Максимальная степень аккумуляции выявлена для цинка. По степени возрастания средней концентрации тяжелых металлов в плодах шиповника элементы можно расположить в следующий ряд (мг/кг):

$$
\mathrm{Zn}(8,05)>\mathrm{Pb}(3,65)>\mathrm{Cd}(0,06) \text {. }
$$

При этом, количество тяжелого металла в исследуемых образцах определяется степенью антропогенной нагрузки. Максимальные значения 8,57 мг/кг для цинка, 5,02 мг/кг для свинца и 0,08 мг/кг для кадмия выявлены в плодах шиповника однорядовых насаждений вдоль автотрассы «Курск Курчатов» на расстоянии 4 м от нее.

Содержание свинца и кадмия во всех исследованных образцах не превышает ПДК, установленных в Государственной фармакопее РФ для лекарственного растительного сырья и лекарственных растительных препаратов, а цинка - ПДК для сухих фруктов и ягод и находится в пределах нетоксичных концентраций.

В соответствии с этим плоды шиповника майского, собранные в Октябрьском районе Курской области, не представляют опасности с точки зрения накопления тяжелых металлов и могут быть рекомендованы для сбора, заготовки и использования в пищевых целях.

Следует отметить, что проблема нормирования содержания тяжелых металлов в лекарственных растениях на территории РФ до настоящего времени полностью не решена и требует дальнейшего рассмотрения.

\section{Список литературы}

1. Неверова О. А., Егорова И. Н. Оценка качества плодов шиповника (ROSA MAJALIS HERRM.), произрастающего на породном отвале угольного разреза в условиях Кемеровской области // Техника и технология пищевых производств. - 2015. - Т. 38, №3. - С. 139-143. 
2. Каманина И. 3., Каплина С. П., Салихова Ф. С. Содержание тяжелых металлов в лекарственных растениях. // Научное обозрение. - 2019. - №1. - С. 29-34.

3. Скорбач В. В., Костенко А. Ю. Содержание тяжелых металлов (биоэлементов) в лекарственных растениях при различном удалении от защитной лесополосы // Пространственно-временные аспекты функционирования биосистем: сб. материалов XVI международной научной экологич. конференции, посвященной памяти А.В. Присного. - Белгород, 2020. - С. 254-257.

4. Скугорева С. Г., Яшихмина Т. Я., Фокина А. И., Лилина Е. И. Химические основы токсического действия тяжелых металлов (обзор) // Теоретическая и прикладная экология. - 2016. - №1. - С. 4-13.

5. Пелихович Ю. В., Бегдай И. В., Харин К. В., Цесарь Т. А. Аккумуляция тяжелых металлов в лекарственных растениях и оценка рисков при их употреблении // Наука. Инновации. Технологии. - 2020. - №4. - С. 171-182.

6. Пименова М. Е., Шелепова О. В. Природное разнообразие содержания тяжелых металлов в дикорастущих лекарственных растениях в сравнении с нормативами ПДК. [Электронный ресурс]. - Режим доступа: URL: https://cyberleninka.ru/article/n/prirodnoe-raznoobrazie-soderzhaniya-tyazhy olyh- metallov-v-dikorastuschih-lekarstvennyh-rasteniyah-v-sravnenii-s-normativa mi-pdk/viewer (дата обращения 10.02.2022).

7. ОФС.1.5.3.0009.15. Определение содержания тяжелых металлов и мышьяка в лекарственном растительном сырье и лекарственных растительных препаратах [Электронный ресурс]. - Режим доступа: URL: https://pharmaco poeia.ru/ofs-1-5-3-0009-15-opredelenie-soderzhaniya-tyazhelyh-metallov-imyshyaka-v-lekarstvennom-rastitelnom-syre-i-lekarstvennyh-rastitelnyhpreparatah/ (дата обращения 10.02.2022).

8. СанПиН 42-123-4089-86. Предельно допустимые концентрации тяжелых металлов и мышьяка в продовольственном сырье и пищевых продуктах [Электронный ресурс]. - Режим доступа: URL: https://files. stroyinf.ru/Index2/1/4293731/4293731790.htm (дата обращения 10.02.2022).

9. СанПиН 2.3.2.560-96. Гигиенические требования к качеству и безопасности продовольственного сырья и пищевых продуктов [Электронный pecypc]. - Режим доступа: URL: https://docs.cntd.ru/document/9052436 (дата обращения 10.02.2022). 
10. СанПиН 2.3.2.1078-01. Продовольственное сырье и пищевые продукты. Гигиенические требования безопасности и пищевой ценности пищевых продуктов [Электронный ресурс]. - Режим доступа: URL: https://docs.cntd.ru/document/901806306 (дата обращения 10.02.2022).

11. МУК 4.1.1501-03 Методические указания. Методы контроля. Химические факторы. Инверсионно-вольтамперометрическое измерение концентрации цинка, кадмия, свинца и меди в пищевых продуктах и продовольственном сырье [Электронный ресурс]. - Режим доступа: URL: https://docs.cntd.ru/document/1200034797 (дата обращения 10.02.2022).

12. Уджуху С. Р. Оценка влияния автотранспорта на содержание свинца в почве и растениях // Известия вузов. Северо-Кавказский регион. Естественные науки. Приложение. - 2005. - №5. - С. 70-74.

13. Щукин В. М., Кузьмина Н. Е., Швецова Ю. Н., Лутцева А. И. Сравнительный анализ содержания тяжелых металлов и мышьяка в различных лекарственных формах растительных препаратов российского фармацевтического рынка // Ведомости научного центра экспертизы средств медицинского применения. - 2020. - Т. 10, №1. - С. 41-50.

14. Димиденок Ж. А., Смирнова С. А. Экологическая безопасность плодово-ягодного сырья южной зоны Приамурья // Технологии производства и переработки сельскохозяйственной продукции: сборник научных трудов. Благовещенск: Изд-во Дальневосточного государственного аграрного университета, 2019. - Вып. 17. - С. 48-52.

(C) О.В. Лукьянчикова, Д.В. Шевченко, 2022 